\title{
El universo simbólico entorno de la sociedad de la beneficencia en la política social argentina*
}

\author{
Susana Moniec ${ }^{* *}$
}

RESUMEN

En base a la historia de la Sociedad de la Beneficencia Argentina y a partir de la perspectiva teórica que brindan Alfred Schutz (1995), Peter Berger y Tomas Luckman (2005), en éste artículo se describe y analiza la forma en que funcionan algunos símbolos, que ésta institución instaló, en la construcción de un campo de significado para la intervención social.

Palabras clave: Sociedad de la Beneficencia / Intervención Social / Política asistencial argentina.

\section{The symbolic universe around the society of charity in the argentinian social policy}

ABSTRACT

Based on the history of the Argentinian Society of Charity and from the theoretical perspective posited by Alfred Schutz (1995), Peter Berger and Tomas Luckman (2005), this article describes and analyzes the way in which some symbols, established by this institution, function in the construction of a field of significance for social intervention.

Key words: Society of Charity / social intervention / Argentinian Welfare Policy

* Este artículo fue presentado originalmente con el nombre correspondiente a "El universo simbólico en torno de la sociedad de la beneficencia"

** Argentina. Trabajadora Social. Docente investigadora de la Universidad Nacional de Misiones. Correo electrónico: sumoniec@invs.unam.edu.ar 


\section{Introducción}

La intervención orgánica del Estado Argentino sobre la cuestión social, puede ser clasificada en tres grandes etapas, cada una de ellas vinculadas a diferentes modelos de desarrollo. El Modelo de la Beneficencia, vinculado al Modelo Agro Exportador de desarrollo económico, se caracterizó por el crecimiento hacia fuera y por una escasa intervención del Estado sobre la cuestión social, que en la época no se configuraba aún en términos modernos.

Este periodo se extendió hasta la década del '30, cuando comenzó a desarrollarse el Modelo de Sustitución de Importaciones, momento en que en el país se instala con toda su fuerza la cuestión social en términos modernos; debiendo asumir entonces, el Estado un papel mas activo de intervención sobre lo social, configurándose gradualmente un nuevo perfil de política social, que unas décadas mas tarde daría lugar al Estado de Bienestar Social Argentino. Estado de Bienestar que algunos autores (Lo Vuolo y Barbeito: 1993) lo caracterizan como un híbrido institucional en virtud de que conjugó características de los modelos de la Seguridad Social (Beveridge), del Seguro Social (Bismarck) y del Asistencial.

La tercera etapa del desarrollo de las políticas sociales en Argentina comienza a perfilarse con el auge de las políticas de ajuste, que van a propiciar nuevos paradigmas de política social para el país, fundamentalmente a partir de la intervención de los organismos acreedores. Comienza a sostenerse entonces la necesidad de hacer más eficiente y eficaz el gasto social del Estado, para lo cual se propone un modelo de política social a partir del cual se focalice la intervención social del Estado en la extrema pobreza. Este paradigma de política social tuvo su máximo desarrollo durante la década del ' 90 .

En este trabajo se pretende abordar el primero de estos modelos de intervención sobre lo social, que tuvo a la Sociedad de la Beneficencia como una institución emblemática, que por más de un siglo se encargó de la atención de la cuestión social en el país, formateando muchas prácticas que aún hoy tienen vigencia. El objetivo del trabajo, más específicamente es analizar el mundo simbólico que se establece a partir de la intervención de la "Sociedad de la Beneficencia" en la política social en Argentina.

En ese sentido, en primer término se reseña la historia de la consti- 
tución de la Sociedad de la Beneficencia Argentina, que tuvo vigencia desde su creación, en el año 1823 hasta el año 1946, cuando fue intervenida. En base a la historia de esta institución se identifican y describen los símbolos que instaló la misma, para finalmente proceder al análisis de la forma en que funcionan estos símbolos en la construcción simbólica de la realidad social en el campo de la intervención social del período. Para el análisis se ha adoptado la perspectiva teórica que brindan Alfred Schutz (1995) y Peter Berger y Tomas Luckman (2005), quienes proporcionan elementos para comprender la construcción simbólica de la realidad social.

\section{Reseña histórica de la constitución e intervención social de la sociedad de la Beneficencia en la argentina durante su vigencia (1823-1946)}

El modelo de intervención de la Beneficencia argentina que se inicia con la creación de la Sociedad de la Beneficencia en 1823 y se extiende hasta la crisis del treinta, cuando se redefine la cuestión social en términos modernos y comienza a producirse el ocaso de la misma', es indicado por diferentes autores (Fanfani: 1989; Alayon: 1978) como una de las primeras estrategias de intervención estatal en materia social.

Antes de que el Estado comenzará a intervenir de manera mas orgánica sobre la cuestión social con la creación² de la Sociedad de

1 Esta institución fue intervenida en el año 1947, pasando en el año 1948 a integrar la Dirección Nacional de Asistencia Social.

2 José Luis Moreno (2000), establece diferentes etapas en el desarrollo del Estado de Bienestar Argentino, dos de las cuales las sitúa justamente antes de la creación de la Sociedad de la Beneficencia. La primera, durante el periodo colonial hasta 1779, en que se crea la casa de Niños Expósitos, que se caracteriza por la ausencia casi total del Estado imperial español en la asistencia a las problemáticas sociales de la época. Siendo las cofradías y órdenes religiosas las que manejaban estos asunto. La segunda etapa, va de 1779 a 1823 y se caracterizaría por los primeros atisbos de una política estatal a los niños abandonados. La tercera y cuarta etapa se vinculan con la historia de la Sociedad de la Beneficencia, una desde el momento de su fundación en 1823 a 1852, en que se la vuelve a reinstalar, después que cae el gobierno de Rosas y la cuarta de consolidación y crecimiento institucional de la Sociedad. "Etapa fundacional de la moderna beneficencia por la cantidad de instituciones creadas y la cantidad de prestaciones realizadas" (Moreno 2000: 12).

La quinta etapa en el desarrollo del Estado de Bienestar Argentino la sitúa entre 
la Beneficencia, existían otras instituciones de acción social, que funcionaron en el Río de la Plata y que en aquel entonces estaban en manos de la hermandades religiosas, como hospitales; colegios de huérfanas; hospitales de mujeres; casas de niños expósitos, entre otras. Asumiendo la Iglesia, a través de sus ordenes religiosas y con el apoyo económico 3 proveniente de donaciones de los ciudadanos, el abordaje de la problemática social de la época de la colonia (salud, niñez abandonada, educación, pobreza). En esa época, que abarcó los siglos XVII y XVIII, Buenos Aires era un pequeño poblado integrado mayoritariamente por blancos y en menor número por mestizos, mulatos y negros.

En aquel entonces, en que el poblado aún no contaba con importante infraestructura urbana y en que aún no se habían producido los adelantos de la medicina moderna, las enfermedades y epidemias (viruela, tifus, tuberculosis, peste bubónica, rabia), dejaban muchos huérfanos y viudas, que en el caso de las mujeres ${ }^{4}$ constituía un grave problema social. Inhabilitadas para trabajar, sumidas en la pobreza y sin posibilidades de mantenerse, la alternativa era convertirse en beatas ${ }^{5}$ o integrarse a los colegios o casas de recogimiento de huérfanas que funcionaban en la época y a los cuales se les asignaba la función de ampararlas, instruirlas y casarlas. Estas, casas de recogimiento también funcionaron como escuelas para las hijas de las principales familias porteñas, cuyos padres permitían que sus hijas

los años 1893-1946. Esta etapa es descripta por Moreno (2000), como de un periodo de fuerte consolidación política y encumbramiento aún mayor de las damas que la conducían. En ese periodo también tuvo un "aporte creciente y sostenido del estado para una cantidad cada vez mayor de instituciones que cumplieron los mas variados fines". (Moreno 2000: 13).

3 En general, los autores que describen la situación de las instituciones que se encargaban de los problemas de los huérfanos y niños abandonados y de los problemas de salud de la población se encontraban permanentemente con inconvenientes de tipo económico para sostener estas instituciones. Los sucesivos gobiernos de la época no aportaban fondos de manera sistemática y suficiente.

4 Debemos recordar que en la época las mujeres tenían un ámbito de acción circunscrito a las tareas del hogar; el lugar reservado para ella por los hombres fue el de sostenimiento y promoción de la moral y las buenas costumbres y por ello el involucramiento en las actividades de la Sociedad de la Beneficencia y actividades de caridad, constituyeron los primeros espacios públicos en los cuales participaron las mujeres de la época.

5 Se trataba de una "profesión religiosa de carácter no conventual" que consistía en hacer "votos privados de castidad para dedicarse a al ejercicio de la caridad y la oración, viviendo en un estado de semi reclusión" (BIROCCO 2000: 22). 
recibieran educación; como lugar de reclusión y disciplinamiento de esposas y novias que transgredían las pautas de comportamiento establecidas para las mujeres en la época.

Con la creación del Virreinato del Río de la Plata (1776-1810), la población aumentó sostenidamente, la ciudad se expandió así como los organismos encargados de velar por las cuestiones de orden público y social, como la salud, la seguridad, la higiene, la protección de pobres e infantes.

Otros de los graves problemas sociales de entonces, que se extendieron conjuntamente con la ciudad fueron por un lado, el abandono sistemático de niños recién ${ }^{6}$ nacidos, para quienes fue creada en 1779 la Casa de Niños Expósitos ${ }^{7}$, que por lo menos en su primera etapa, hasta antes de ser traspasada su administración a la Sociedad de la Beneficencia, nunca contó con los fondos suficientes para el abordaje del problema que se le había encargado. Por otra parte, los problemas de la mendicidad ${ }^{8}$ y la vagancia, fueron reprimidos con medidas que iban desde la expresa prohibición por parte de las autoridades de mendigar o vagar, la reclusión en asilos especiales, el destierro a los castigos físicos.

6 COWEN (2000) hace referencia a que se convertían en expósitos los niños productos de embarazos privados en los cuales las mujeres enfermaban nueve meses, para después del parto recobrar su virginidad. Al respecto MORENO (2000) aporta interesantes datos cuando en su investigación rescata informes que obran en el Archivo General de la Nación, dónde consta que la casa de Expósitos fue creada con el objeto de albergar a los niños producto de relaciones prohibidas y evitar así el deshonor. Asimismo, el mismo autor coloca, que como en sus primeros tiempos esta Institución funcionó mediante el mecanismo de Torno, las esclavas aprovecharon para liberar de este modo de la esclavitud a sus hijos.

7 Una cuestión interesante apuntada por MORENO (2000) y también por GALLO (2002), es que esta institución estuvo regenteada por una rectora y contaba como colaboradoras a mujeres que eran reclutadas de los estratos mas bajos de la sociedad, que cuidaban de los niños, muchas de ellas se dedicaban a amamantarlos. Gallo (2002) destaca que estas mujeres "ejercían su oficio urgidas por la necesidad de sus frágiles familias, aún cuando el salario era magro y a duras penas lograban escapar de la pobreza. Por contrato tenían la obligación de dejar de amamantar a sus hijos pero en realidad acababan dividiendo su alimento entre el propio y el ajeno. Esto provocaba una grave desnutrición para ambos" (GALLO 2002: 98-99). Al respecto MORENO (2000) da cuenta de una mortalidad institucional de los niños expósitos del $55 \%$ de los niños ingresados cada año.

8 El problema de la mendicidad llamaba poderosamente la atención de los extranjeros que visitaban Buenos Aires de la época, incluso existen varios grabados de la época donde se los retrata con el cartel identificatorio, colocado a la altura del pecho que eran obligados a llevar (GALLO 2002) 
La Revolución de Mayo de 1810, trajo consigo una reforma administrativa, política y eclesiástica, se secularizaron muchas de las funciones que antes eran cumplidas por los clérigos. "A fin de cuentas, el trascendental reordenamiento legal impulsado por el gobierno afectó muchos intereses de las comunidades religiosas, incluyendo sus instituciones. (...) Las migajas que quedaron de tan zarandeadas congregaciones y agrupaciones caritativas (...) fueron entregadas a la incipiente Sociedad de la Beneficencia." (GALLO 2002: 137).

Los autores analizados, plantean diferentes etapas en el accionar de esta institución. Faciuto (2005) plantea dos etapas, una de la creación, bajo el influjo de la corriente filantrópica y la otra influida por la corriente médico higienista. La primera va desde la creación de la Sociedad en 1823 a finales del Siglo XIX; la otra, desde ahí a su disolución en 1946.

Por su parte, Moreno (2000) encuadra el funcionamiento de la Sociedad de la Beneficencia en tres de las etapas de desarrollo del Estado de Bienestar Argentino que para el autor inicia ya en el periodo colonial (1779), así la tercera, cuarta y quinta etapa del desarrollo de esta institucionalidad, se vincula con la historia de la Sociedad de la Beneficencia. La primera de ellas la sitúa desde el momento de la fundación en 1823 hasta 1852, en que se la vuelve a reinstalar, después que cae el gobierno de Rosas; la otra, de "consolidación y crecimiento institucional de la Sociedad", a la que caracteriza como "Etapa fundacional de la moderna beneficencia por la cantidad de instituciones creadas y la cantidad de prestaciones realizadas" (Moreno 2000: 12).

La quinta etapa en el desarrollo del Estado de Bienestar Argentino la sitúa entre los años 1893-1946. Esta etapa es descripta por Moreno (2000), como de un periodo de fuerte consolidación política y encumbramiento aún mayor de las damas que la conducían. En ese periodo también tuvo un "aporte creciente y sostenido del estado para una cantidad cada vez mayor de instituciones que cumplieron los más variados fines" (Moreno: 2000: 13).

En este trabajo se focaliza el análisis en la producción simbólica de lo que podríamos denominar etapa fundacional, desde la creación de la Sociedad hasta principios de siglo XX, momento que se caracteriza por el influjo de la corriente filantrópica, en términos de Faciuto (2005). 
La Sociedad de la Beneficencia, se estableció como "una sociedad de damas", mediante un Decreto suscrito el 2 de enero de 1823, por el Gobernador de la Provincia de Buenos Aires, en aquel entonces Martín Rodríguez, que fue refrendado por el Ministro Secretario de Gobierno Bernardino Rivadavia. En el Decreto se argumentaba que "La existencia social de las mujeres es aún demasiado vaga e incierta. Todo es arbitrario respecto de ellas. Lo que a unas vale, a otras pierde; las bellas como las buenas cualidades, a veces las perjudican, cuando los mismos defectos suelen serles útiles"

Fue entonces, en la imperfección de las mujeres que se suponía constituía un obstáculo al progreso de la civilización, que se instala la necesidad de creación de la Sociedad. Se creía "útil y justo acordar una seria atención a la educación de las mujeres, a la mejora de sus costumbres y a los medios de proveer a sus necesidades para poder llegar al establecimiento de leyes que fijen sus derechos $y$ deberes y les aseguren parte de la felicidad que les corresponde" ${ }^{\prime \prime}$.

Para el logro de la perfección de las mujeres, se encomendó la tarea a un grupo selecto de damas de la sociedad, a quienes se les atribuía la capacidad de contribuir con habilidad y eficacia a los fines propuestos: "no hay medio que pueda contribuir con tanta habilidad y eficacia a la asecución de tan importantes fines, como el espíritu público de las damas que, ya por la situación distinguida que han obtenido, como por las dotes de su corazón y de su espíritu, presiden en su sexo y prueban su aptitud"11.

En aquel entonces, se le atribuyó a dicha institución como funciones: "la dirección e inspección de las escuelas de niñas; la dirección e inspección de la casa de expósitos, de la casa de partos públicos y ocultos, hospitales de mujeres, colegio de huérfanas y de todo establecimiento público dirigido al bien de los individuos de ese sexo"12. Muchas de estas instituciones habían estado hasta este momento a cargo de diferentes órdenes religiosas. Así, durante el tiempo en que existió esta institución tuvo a su cargo diversas instituciones: institutos de niños, niñas y mixtos; centros de salud de niños, de mujeres y mixtos e institutos geriátricos.

9 Decreto de Creación. Archivo General de la Nación.

10 Decreto de creación de la Sociedad de la Beneficencia. Archivo General de la Nación.

11 Decreto de creación de la Sociedad de la Beneficencia. Archivo General de la Nación.

12 Decreto de creación de la Sociedad de la Beneficencia. Archivo General de la Nación. 
Desde el año de creación de la Sociedad en 1823 hasta principios de siglo XIX, Buenos Aires experimentó un vertiginoso crecimiento poblacional. Para 1827 contaba con 60.000 habitantes, aumentando tan solo 16 años después, para 1843 a 161.000 habitantes, en tanto para 1909, ya superaba el millón, con una población de 1.240 .000 habitantes.

Dos meses después de su creación, el primero de marzo de 1823, se instituyen los premios de la sociedad: uno a la moral, uno a la industria y dos a la aplicación. Estos premios debían ser adjudicados y repartidos por la Sociedad de la Beneficencia, todos los días 26 de Mayo de todos los años.

Todos los premios consistían en la adjudicación de una suma de dinero (\$200, \$100, \$ 50). El premio a la Moral se otorgaba a "la mujer que más se haya distinguido por su moralidad y por la práctica de las virtudes propias del sexo y de su estado"13. El premio a la Industria se otorgaba a aquella mujer que "mas se haya esmerado en el tesón de adquirir con honradez, por medio de un trabajo industrioso, los medios de subsistencia, o la de sus padres o hijos"14. Los premios a la Aplicación, si bien representaban una suma de dinero, se otorgaba en especies o útiles, "a dos niñas que más se hayan distinguido por sus talentos y aplicación"15.

Si bien las instituciones ${ }^{16}$ bajo la orbita de la Sociedad de la Beneficencia abordaban los problemas sociales de ambos géneros (masculino y femenino), en todos los casos los destinatarios de los premios eran mujeres.

Según el Reglamento para la adjudicación de los premios, el Consejo de la Sociedad, debía publicarlos al principio de cada año, mediante "papeles públicos o carteles fijados en lugares convenientes y particularmente en las parroquias"17.

13 Decreto de fundación de los premios de la sociedad de la beneficencia. Archivo General de la Nación.

14 Decreto de fundación de los premios de la sociedad de la beneficencia. Archivo General de la Nación.

15 Decreto de fundación de los premios de la sociedad de la beneficencia. Archivo General de la Nación.

16 Asilos de huérfanos, de su educación religiosa, de la educación básica en los primeros grados, instrucción en oficios (jardinería, telar, costura, tejido, confección de prendas de diverso tipo, carpintería, tareas agrícola ganaderas); asistencia médica y asilo a mujeres pobres y ancianas, asistencia en el área de salud tanto de mujeres, hombres, niños y niñas.

17 Reglamento para la adjudicación de los premios. Archivo General de la Nación. 
Cada una de las socias era la encargada de identificar a las personas que en base a sus cualidades y circunstancias podrían ser objeto exclusivo del premio. Así, un mes antes de la fecha fijada para la entrega de los premios, cada una de las socias debía presentar una candidata para cada premio. Esta presentación debía hacerse a través de una nota escrita que releve el merito, con los comprobantes; en ella debía indicarse también el nombre, el estado civil, familia y vecindad de la candidata.

Luego mediante un procedimiento interno (lectura de postulaciones, análisis y dictamen de postulaciones por una comisión, y finalmente votación) se definía cada una de las adjudicatarias de los premios; premios que eran entregados en una velada de gala, muchas de ellas realizadas en el teatro Colón. Acto al cual, además de las socias y premiadas, concurrían representantes de diversos sectores encumbrados de la sociedad porteña, del clero y de la política.

En el Reglamento también se establecía el procedimiento que debía seguirse al momento de la entrega. Así, las premiadas debían ser colocadas en un lugar distinguido de la sala donde se efectuaba el acto de entrega; luego conducidas ante la presidenta de la sociedad; la cual procedería a la entrega de los premios, que se efectuaba en el siguiente orden: primero se entregaba el premio a la Moral y las Virtudes; luego a la Honradez y la Industria y luego a la Aplicación y los talentos de las niñas. Cada uno de los premios debía ser entregado pronunciándose una arenga típica, que para diferenciar cada uno de los premios únicamente reemplazaba la denominación del mismo "la sociedad os entrega este premio con que el celo paternal del gobierno de la Provincia recompensa la moral y las virtudes de vuestro estado. Que él sea un estímulo poderoso para que os hagáis cada vez más digna del aprecio público"18. El circuito se cerraba con la publicación de las ganadoras en los papeles públicos.

Los gastos de funcionamiento de la Sociedad se financiaban con recursos provenientes del Estado y también de donaciones de distintos sectores de la sociedad.

Entre los años 1829 a 1852, periodo de gobierno de Juan Manuel de Rosas, la Sociedad vio reducidos los aportes financieros del Estado. El gobierno de Rosas, en principio, comenzó a exigir a esta institu-

18 Reglamento para la adjudicación de los premios. Archivo General de la Nación. 
ción el rendimiento del dinero otorgado en tiempo y forma, imponiéndole la "Ley de Contabilidad"; luego argumentando el estado de bloqueo que ocurría en el país en la época, redujo el presupuesto destinado a los premios a la virtud (1835) y paulatinamente los fondos generales, hasta quitarle el apoyo económico, con lo cual la institución se vio obligada a reducir sus funciones, cerrar instituciones, como la Casa de Niños Expósitos (1938) y financiar sus actividades con aportes privados.

Meyer (1911) explica esta situación en el hecho de que Rosas veía en la Sociedad de la Beneficencia, fundamentalmente en los primeros años de su gobierno, un lugar que albergaba conspiradores a su régimen de gobierno. Esto porque las damas habían elegido como nuevas socias a hermanas y esposas de quienes el consideraba conspiradores. Hay que recordar que el funcionamiento de la sociedad, durante el gobierno de Rosas se dio en el marco de las sangrientas luchas entre unitarios y federales.

Interesante de este periodo es que en el año 1845 las damas que presidían la institución, muchas de ellas esposas de colaboradores de Rosas, habían colocado en la presidencia de la Sociedad de Damas a la hermana de Rosas y crearon el cargo de Socia Presidenta, Protectora del Colegio de Huérfanas para la hija de Rosas, quien rechazó el nombramiento.

Desde su creación y hasta finales del siglo XIX, las instituciones bajo la orbita de la Sociedad de la Beneficencia se concentraron básicamente en el abordaje de la problemática de los niños y niñas huérfanos o abandonados; a partir del siglo XX, paralelamente a la intervención vinculada a los huérfanos y abandonados, cobró más fuerza la intervención en el área de la salud, período en el que se crearon instituciones para atender distintas problemáticas vinculadas a la higiene y salud: hospitales, maternidades, dispensarios, sanatorios.

Esta institución fue intervenida en el año 1947, siendo finalmente absorbida, en el año 1948, por la Dirección Nacional de Asistencia Social, creada ese año.

La forma de intervención social que institucionalizó la Sociedad de la Beneficencia, formateó algunas de las características de la política social de asistencia en la Argentina; características que aún hoy 
persisten; entre ellas Fanfani (1989) menciona el sesgo femenino de la acción social, la discrecionalidad en la prestación u otorgamiento de los beneficios y la autonomía de la política social respecto de la pobreza.

\section{Símbolos que instala la Sociedad de la Beneficencia como institución de la política social Argentina}

Una de las características de la política social argentina y en particular de la política de asistencia a lo largo de su historia, entendida esta como una intervención orgánica del Estado a partir de la cual se articulan procesos políticos y económicos, es la participación de las mujeres en su ejecución, ya sea en su carácter de "Damas de la Alta Sociedad" (Sociedad de la Beneficencia); como esposas de gobernantes o familiares directos (Evita, Chiche Duhalde, Alicia Kirchner); o como profesionales del Trabajo Social o Asistencia Social, entre otras formas de manifestación (punteras barriales, Manzaneras).

Esta situación nos lleva a colocar en este campo a la mujer como símbolo y a preguntarnos cuando y como es que se instala en la sociedad argentina esta cuestión de género como gravitante en el abordaje de la cuestión social. Ahí es donde aparecen como significativos los aportes de Peter Berger y Thomas Luckman (2005), quienes destacan la importancia del lenguaje como un sistema de signos y en tanto tal, caracterizado por su "separatividad", por su "capacidad de comunicar significados que no son expresiones directas de subjetividad "aquí y ahora... el lenguaje es capaz de transformarse en depósito objetivo de vastas acumulaciones de significado y experiencia, que puede preservar a través del tiempo y transmitir a generaciones futuras" (Peter Berger y Thomas Luckman 2005: 54).

Para comprender esta cuestión es útil adentrarse en la historia de la primera institución a partir de la cual el Estado intervino orgánicamente sobre la problemática social argentina. En ese sentido, se podría interpretar a la institución de la Damas de la Sociedad de la Beneficencia como una objetivación de la realidad de la vida cotidiana, que proclama las intenciones subjetivas de un determinado sector de poder de la sociedad argentina de la época, fundamentalmente de los hombres de la clase dominante, quienes asignaban a las mujeres de dicha clase atributos y saberes específicos, dife- 
rentes de los hombres, que las habilitarían para encargarse de los problemas sociales. A diferencia de las "Damas", las mujeres pobres y las asistidas eran preparadas para desempeñarse como sirvientas, mucamas, damas de compañía, niñeras y cocineras (domésticas). En este sentido, mediante el lenguaje y las categorías propias de la época se construyó la diferencia, que permanentemente fue marcada en el accionar de las estas mujeres mediante rituales e índices.

En los diferentes documentos primarios analizados ${ }^{19}$ se puede observar la instalación de la mujer como símbolo que conjuga la imperfección moral e intelectual, "que obstaculizan el progreso de la civilización", con otros atributos que no posee el hombre, como las "dotes del corazón", "la sensibilidad", "la dulzura", "la afabilidad" y "el espíritu", "que contribuyen decididamente a la formación de la moral" y que complementarían las ideas y sentimientos del hombre. Concomitantemente con el pensamiento de la época, se le asigna al orden de la naturaleza la construcción social de la figura de la mujer como inferior a la del hombre.

Los atributos de cuales las mujeres eran poseedoras, justificaron entonces la instalación de la obligación moral (para las "mujeres distinguidas"), de prestar servicios y no recusarse a trabajar en la mejora de las costumbres y de los medios para proveer a las necesidades de las mujeres "para poder llegar al establecimiento de leyes que fijen sus derechos y sus deberes y aseguren la parte de felicidad que les corresponde" (Decreto de establecimiento de la Sociedad. AGN- Archivo General de la Nación).

Esta concepción de que la mujer necesitaba perfeccionar su moral, se legitima a partir de la instalación de instituciones educativas, a cargo de las Damas de la Sociedad de la Beneficencia en las cuales se deposita la misión de "atención a la educación de las mujeres, a la mejora de las costumbres y a los medios de proveer a sus necesidades para poder llegar al establecimiento de leyes que fijen sus derechos y deberes..." (Decreto de Creación de la Sociedad, AGN).

Se podría interpretar que los premios otorgados por la sociedad, simbolizan el tipo de comportamiento social, deseable para las mu-

19 Decretos de establecimiento de la Sociedad de la Beneficencia; Decreto de organización de la Sociedad de la Beneficencia; Decreto de Fundación de premios; Documentación de instalación de la Sociedad, entre otros. Archivo General de la Nación. 
jeres de la época: la conducta moral; el esmero y honradez para adquirir por medio del trabajo industrioso los medios de subsistencia y la premiación de las niñas que más se hayan distinguido por su talento.

Estos premios involucraban un ritual que implicaba la selección de candidatas; la realización de un acto público con presencia de autoridades y representantes de diferentes sectores de la sociedad, en el cual se presentaban las "agraciadas a recibir los premios" instancia en la cual se les asignaba un lugar destacado; se leía el acta de adjudicación; se acompañaba a la "agraciada" hasta el lugar de la presidenta para entregarle el premio con la pronunciación de una arenga y finalmente se daba a publicidad el nombre de las ganadoras.

Mediante el procedimiento de adjudicación de los diferentes premios que promovía la Sociedad como estimulo para el perfeccionamiento social de las mujeres, recompensando la moral y la virtud, también se instala la discrecionalidad como práctica de la política social de asistencia, en el otorgamiento del beneficio. Eran las socias (mujeres correspondientes a sectores poderosos de la sociedad) quienes definían a las merecedoras.

La forma en que se fue desarrollando la atención a los problemas sociales de la época, contribuyeron a la constitución de hábitos en torno de la política de asistencia, que se institucionalizaron luego de ocurrida la tipificación de las acciones que habitualmente eran desarrolladas por los actores intervinientes en el campo (damas de la sociedad, políticos de la época, receptores de servicios). Tipificación que como forma de abstracción condujo a conceptualizaciones estandarizadas, que permitieron la construcción de categorías que se volvieron anónimas, trascendiendo el contexto en el cual se originaron.

A partir del mundo simbólico construido por la intervención de la Sociedad de la Beneficencia sobre la cuestión social de la época, se establecieron entidades sociales; así mediante referencias apresentacionales se ordenaba el mundo de lo social. Ese mundo simbólico pasó a organizar y regular la vida cotidiana e influir en la acción de los individuos, ya que contribuyó en el establecimiento de padrones típicos de relación entre el dador y el receptor de un servicio; estableció rituales y pautas de comportamiento para acceder a ser merecedor de servicios y premios como los galardones a la virtud, 
a la moral y la industria que año a año entregaban las damas de la Sociedad.

La intervención fundamentalmente femenina sobre la cuestión social, tendría un poder indicativo y se instala como un símbolo que viene a suplir la falta de atención del Estado sobre los problemas sociales que aquejaban a la región en la época analizada.

La Sociedad de la Beneficencia funcionó como una institución monopólica de atención a la cuestión social en tanto el simbolismo que proponía y en tanto los procesos y mecanismos de legitimación brindaron explicaciones plausibles, posibles de ser aceptadas por el conjunto de la sociedad. Esta plausibilidad se fue perdiendo cuando el contexto social fue cambiando y comenzó a aparecer en el escenario argentino el problema social en términos modernos, que obligó a que el Estado modificara su rol, haciéndose presente con mayor fuerza en el campo de la intervención social, a partir de la participación y un mayor control en las instituciones y en la generación de políticas.

Lo Vuolo y Barbeito, explican que "hacia fines del siglo XIX y comienzos del XX, el ambiente político se fue modificando. Después de la reforma electoral de 1912, (...) se intensificó la presión de ciertos grupos sociales sobre las instituciones del Estado" (1998: 115)

En ese entonces, los marcos que la Sociedad de Damas de la Beneficencia ofrecían para explicar y justificar la intervención social, basados en la conducta moral, dejaron de ser plausibles ante la diversificación y complejización de la problemática social, que con la consolidación de los derechos políticos (al voto) de los hombres contribuyeron para la modificación de las relaciones de poder vigentes en la sociedad argentina. Esta modificación del contexto político, social y económico propició el surgimiento de nuevos especialistas que comenzaron a disputar el campo de lo social, antes casi exclusivo de la Damas.

\section{Conclusiones}

La lectura comparada de los autores nos permite recuperar la importancia que estos asignan a la utilización de relaciones signantes y simbólicas, a la capacidad de simbolización, sin la cual la vida social no sería posible. La simbolización nos permite la interacción en 
un aquí y ahora, pero también en las otras dimensiones del mundo social, que trascienden ese aquí y ahora. Sin la capacidad de simbolización no habría posibilidades de comprensión de los otros, ni posibilidades de trascendencia.

En este proceso de simbolización, el lenguaje adquiere una relevancia fundamental, ya que interviene en la tipificación de las experiencias, en la construcción de sistemas de referencias apresentacionales que constituyen conocimiento socialmente aprobado. Mediante el leguaje se construyen objetivaciones que disponen un determinado orden a las cosas, orden dentro del cual la vida cotidiana adquiere sentido.

En el caso analizado en este trabajo, observamos que a través del lenguaje se objetiva la experiencia de la Sociedad de la Beneficencia. Así, esta experiencia de la sociedad integrada por mujeres haciéndose cargo de la cuestión social, se tipifica lingüísticamente en la categoría "las mujeres son más aptas", "dóciles" para atender los problemas sociales. Así tipificada adquiere sentido para los actores directamente involucrados, así como para los otros sectores de la sociedad de la época. Pero a su vez, por la capacidad del lenguaje de trascender el aquí y ahora, torna esa experiencia en anónima, y a su tipificación (significado) en repetible por los actores del campo, integrándola de ese modo a la realidad de la vida cotidiana, como un todo significativo. Así podemos considerar el sentido de la asistencia social como cosa de mujeres como una tipificación del lenguaje.

Si bien el universo simbólico establecido en torno a la Sociedad de la Beneficencia en tanto construcción social, se modificó junto con la organización social, la suma de objetivaciones lingüísticas que corresponden al campo semántico de la política social se acuñaron a través del tiempo, formando un acopio social de conocimiento que se transmite de generación en generación y están al alcance del individuo en la vida cotidiana, ordenan significativamente todos los sucesos rutinarios de los diferentes actores involucrados en la gestión de las políticas sociales.

Así, la significación de que el recurso que se otorga constituye un bien propio del dador, a quien el receptor debe agradecer y debe un favor, instaló relaciones asimétricas y clientelares que prepasan el campo de la política social y el Trabajo Social. Pero por otra parte, 
como lo expresa Berger y Luckman, "éste acopio social abarca el conocimiento de mi situación y de sus límites; de modo que la participación en él permite la ubicación de los individuos en la sociedad y el manejo apropiado de ellos" (2005: 58). El favor se debe agradecer con la lealtad política, lealtad que a su vez será recompensada con nuevos favores, manteniéndose de ese modo las relaciones patrón-cliente.

\section{Referencias Bibliográficas}

ALAYON, N. (1978). Antecedentes Del trabajo Social en la Argentina. LIMA: CELATS.

ARANA, M. (1911). Rosas y la Sociedad de la Beneficencia. Buenos Aires: Imprenta de Gerónimo Pesce.

BERGER, P. Y LUCKMAN, T. (2005).

La construcción social de la realidad. Buenos Aires: Amorrortu.

BIROCCO, C. (2000). La primera casa de recogimiento de huérfanas de Buenos Aires: el beaterio de Pedro de Vera y Aragón (1692-1702). En Moreno, J. L. (Comp.). La política social antes de la Política Social. Caridad, beneficencia y política social en Buenos Aires, siglos XVII a XX. Buenos Aires: Trama editorial/Prometeo.

COWEN, P. (2000). N N N N $\quad$ incimientos, partos y problemas de la primera infancia fines del siglo XVIII, primeras décadas del Siglo XIX. En Moreno, J. L. (Comp.). La política social antes de la Política Social. Caridad, beneficencia y política social en Buenos Aires, siglos XVII a XX". Buenos Aires: Trama editorial/Prometeo.

CRESPI, L. (1999). Instituciones de la Sociedad de la Beneficencia y Asistencia Social (1823-1952) Tomo I. Buenos Aires: Archivo general de la Nación.

FACIUTO, A. (2005). La Sociedad de la Beneficencia. Lo oculto de una época. Buenos Aires: Espacio

FRANCO, R. (1996). Paradigmas de política social para América Latina. Santiago, Chile: CEPAL.

GALLO (Ed.) (2002). Historia de la Beneficencia en Buenos Aires Colonial. Buenos Aires: Corregidor.

LO VUOLO, R. Y BARBEITO, A. (1993).

Reseña Histórica de las políticas sociales. La nueva oscuridad de la política social. Buenos Aires: Ciepp. 
MORENO, J. L. (2000) La casa de niños expósitos de Buenos Aires, conflictos institucionales, condiciones de vida y mortalidad de los infantes 1779-1823. En Moreno, José Luis (Comp.) La política social antes de la Política Social. Caridad, beneficencia y política social en Buenos Aires, siglos XVII a XX. Buenos Aires: Trama editorial/Prometeo.

(2004). Historia de la familia en el Río de la Plata. Buenos Aires: Sudamericana

FANFANITENTI, E. (1989). Estado y pobreza: estrategias típicas de intervención I y II. Buenos Aires: Centro Editor de América Latina.

SCHUTZ, A. (1995). El problema de la realidad social. Buenos Aires: Amorrortu 
